\title{
ON THE JOURNAL OF MILITARY STUDIES
}

You are holding in your hand the fourth printed issue of Journal of Military Studies (JMS). This print version contains volume 5 issues 1 and 2 from the year 2014. As the Editor-in-Chief I am very pleased to see the continuing interest by the military community for the JMS, of which our new record in the number of printed articles - a total of eight - is a clear sign.

The first issue in volume 5 is a special issue on research methods in military science. It originates from a seminar in military science research methods, that was arranged in May 2014 by the Department of Tactics and Operational Art of the Finnish National Defence University. The conference organisers, Professor Jari Rantapelkonen and Ph.D. Juhani Hämäläinen, acted as co-editors in making this special issue. As the conference was held in Finland and its call-for-papers wer in Finnish, the participants turned out to be Finnish, too. This also explains that those three papers that were deemed to be of journal quality in the doubleblind review process and can be read from this issue, were all by Finnish authors. The papers are on narratology as a method by Jan Hanska, on wargaming by Hämäläinen, Sormunen, Rantapelkonen and Nikkarila and on focused interviews by Ulla Anttila. This issue is a special contribution to the methodology discussion in the military sciences, although due to multidisciplinary and multi-method nature of military studies, it does by no means cover completely the methodological choices available in the field.

The second issue in volume 5 is a regular issue that contains four interesting articles. Liwång, Ericson and Bang write about risk-based approaches and their applications in military intelligence and military legal field. Wallenius, Bäccman and Larsson write about military decision making and the personality and situational factors affecting it. Ruff-Stahl presents a novel model that could offer help in strategic decision making. Lillbacka presents an interesting study on modeling special operations principles with WWII operations in Finnish front and finally, Aplak, Kabak and Köse game theory application in the military decision making. So even though there exists a great variety in terms of fields and approaches in this printed issue of Journal of Military Studies, the interest in and contribution to the military field is the umbrella under which all five contributions in the $2^{\text {nd }}$ issue take place. 
I would again like to give my sincere thanks to all the reviewers that have voluntarily reviewed the manuscripts and given invaluable feedback for the authors, thus improving the manuscripts. As I went through the archives of JMS, I calculated that the acceptance rate of manuscripts in JMS is around 50 $\%$ since the first issue. I cannot be more specific, as some authors have used email-based submitting instead of JMS website. Although it could be viewed as a sign of the quality of submitted manuscripts, I think that most people see it as a sign of the strictness of reviewing process. At present, I am reasonably satisfied with that figure as it strikes a balance between JMS being an outlet for also those researchers that are doing their doctoral studies and giving a reasonably quality control for the benefit of the reader. As the editor-in-chief of Journal of Military Studies, I am looking confidently to the future with an expectation that this journal will in the future continue to serve even better its intended purpose as a scientific journal in the field of military studies.

\section{Professor Juha-Matti Lehtonen}

Editor-in-Chief, JMS 